\title{
Conduction defects and mitral annulus calcification
}

\author{
CHANDRA K NAIR, VINCENT RUNCO, GREGORY T EVERSON, \\ ANOUSH BOGHAIRI, ARYAN N MOOSS, SYED M MOHIUDDIN, \\ MICHAEL H SKETCH \\ From Division of Cardiology, Creighton University School of Medicine, Omaha, Nebraska, USA
}

SUMMARY The incidence of conduction defects in patients with mitral annular calcification was studied in 104 patients and 121 matched controls. The patients comprised 49 men and 55 women, whose ages ranged from 42 to 90 years, with a mean of $70 \pm 9( \pm S D)$. The control group consisted of 121 patients without mitral annular calcification, whose ages ranged from 50 to 90 years, with a mean of $68 \pm 8( \pm S D)$; there were 61 men and 60 women. Atrial fibrillation with a slow ventricular response, atrioventricular, or fascicular block were found in 73 patients $(70 \%)$ with mitral annular calcification (37 men and 36 women) compared with 41 patients $(34 \%)$ in the control group (24 men and 17 women). Of the 53 patients with isolated calcification of the posterior mitral annulus, $36(68 \%)$ had conduction defects. Both anterior and posterior mitral annular calcification were present in 43 patients, and $29(67 \%)$ of these had conduction defects. Sixty-eight patients had both mitral annular calcification and aortic calcification and $49(72 \%)$ had conduction defects. In the control group, 20 patients had aortic calcification and only seven $(35 \%)$ had conduction defects. Thus, a significantly increased incidence of conduction defects is present in patients with mitral annular calcification when compared with controls, and this is uninfluenced by sex. The incidence of conduction defects with posterior mitral annular calcification is similar to that found with combined anterior and posterior mitral annular calcification. Aortic calcification, either alone or with mitral annular calcification, is not associated with an increase in the incidence of conduction defects.

Calcification of the mitral valve annulus is generally considered a degenerative process. Various pathological and clinical studies ${ }^{1-6}$ have noted a high incidence of such calcification in the elderly and its frequent association with murmurs, cardiac failure, and conduction defects, and have emphasised the striking distortion of the anatomy of the left ventricle, left atrium, and mitral valve apparatus by massive mitral annular calcification. Its clinical detection in the past was based upon the presence of a C- or J-shaped density within the cardiac silhouette on chest $x$-ray films or at fluoroscopy, but recently echocardiography has been shown to be the more sensitive tool. ${ }^{7}$ With the widespread use of echocardiography, therefore, more patients with mitral annular calcification are being detected, and this apparent increase in the incidence may be attributed to the diagnostic sensitivity of the investigation as well as to the number of echocardiograms now being performed. Though the association of mitral annular calcification and cardiac conduction defects is recognised, ${ }^{1-11}$ the Received for publication 11 October 1979 true incidence of the latter remains uncertain and the purpose of this study was to determine it. Since mitral annular calcification occurs predominantly in the elderly, who are more likely to have cardiac disorders and conduction defects, we also studied a control group.

\section{Subjects and methods}

Consecutive echocardiograms performed at our institution from 1974 to 1978 were reviewed. One hundred and four patients with mitral annular calcification were found (group 1); 121 patients without mitral annular calcification, who were similar to group 1 patients with regard to age and sex distribution, were selected as controls (group 2). The outpatient and hospital records of these patients provided the clinical data, and the incidence of cardiac conduction defects was obtained from an analysis of all the available surface electrocardiograms, undertaken independently without knowledge of the echocardiographic findings.

Echocardiograms were obtained with a com- 
mercially available ultrasonograph using a $1.27 \mathrm{~cm}$, $2 \cdot 25 \mathrm{MHz}$, medium-focused transducer, and a strip chart recorder. Posterior mitral annular calcification was identified when a dense echo, greater than $3 \mathrm{~mm}$ in width, was shown anterior to the left ventricular posterior wall, and moving parallel with it (Fig.). In addition, the longitudinal sweep of the transducer showed cephalad termination of the echoes at the atrioventricular junction. When the transducer was directed caudally, the echoes from the mitral annular calcification faded into the echoes of the posterior left ventricular wall. Anterior mitral annular calcification was identified when the scans from the left ventricle to the aortic root disclosed a continuous band of echoes at the level or plane of the anterior mitral valve leaflet, both in systole and diastole. The anterior mitral annular calcification and the mitral valve leaflet were in continuity with the posterior wall of the aortic root.

Aortic calcification was recognised when thick bands of echoes were seen within the aortic root walls both in systole and diastole. The presence of echoes consistent with aortic calcification, however, was not necessarily associated with aortic valvular calcification or with a reduction in the maximal systolic opening of the aortic valve leaflets.

In the electrocardiograms atrioventricular and fascicular blocks were diagnosed using standard criteria. ${ }^{12} 13$ An intraventricular conduction defect was diagnosed in the presence of a QRS duration equal to or greater than $120 \mathrm{~ms}$ but not meeting the criteria for complete right or left bundle-branch block. Atrial fibrillation and/or flutter with a slow ventricular response (defined as less than 60 beats/ minute) was considered significant only if drugs were not being given.

Statistical analysis was performed using $\chi^{2}$ and Student's $t$ test whenever appropriate.

\section{Results}

The clinical data of the 104 patients in group 1 and the 121 patients in group 2 are summarised in Table 1 . The age range was 42 to 90 years, with a mean of $70(\mathrm{SD}=9)$ in group 1 and 50 to 90 years, with a mean of $68(S D=8)$ in group 2 . There were 49 men and 55 women in group 1 and 61 men and 60 women in group 2. Echocardiography was performed for a cardiac murmur in 66 patients in group 1 and 58 patients in group 2, and to evaluate left ventricular function in 29 patients from group 1 and 54 from group 2. Nine patients in each group underwent echocardiography for miscellaneous reasons, such as pericardial effusion, atypical chest pain, and the detection of a possible source of systemic emboli.

A systolic ejection murmur along the left sternal border or at the second right intercostal space suggesting left ventricular outflow tract obstruction or an aortic valve origin was present in 67 patients in group 1 and 54 patients in group 2. A holosystolic murmur heard best at the apex and consistent with mitral regurgitation was present in 17 patients in group 1 and 21 patients in group 2. Ten patients in group 1 and 11 patients in group 2 had an early diastolic decrescendo murmur along the left sternal border consistent with aortic regurgitation. A mid-diastolic murmur at the apex with or without presystolic accentuation suggestive of mitral stenosis was present in seven patients in group 1 and four patients in group 2; in none of these patients, however, was there the anterior motion of the posterior leaflet of the mitral valve characteristic of rheumatic mitral stenosis. Eleven patients in group 1 and nine patients in group 2 had a combination of two or more murmurs.

Twenty-six patients in group 1 and 37 in group 2 had hypertension. Diabetes mellitus was present in

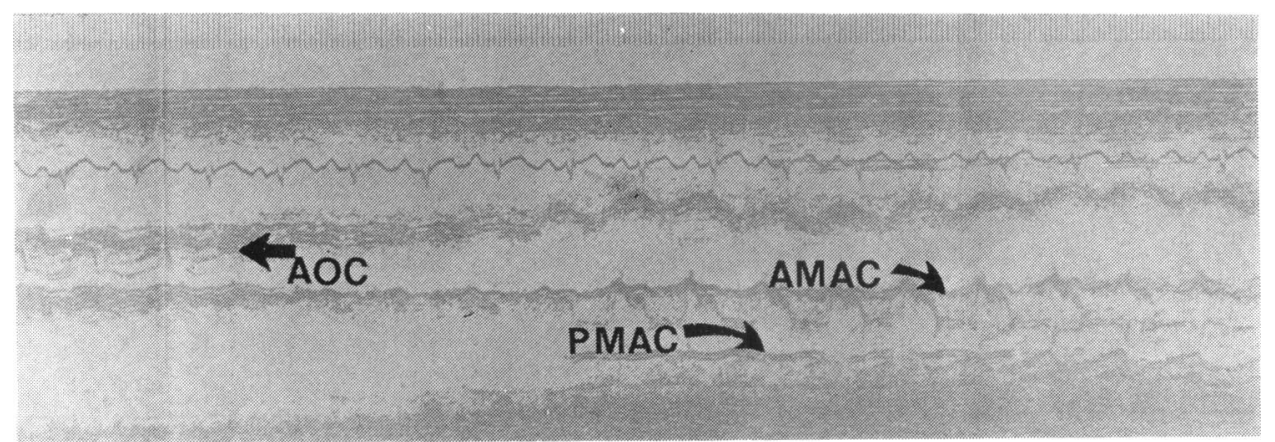

Fig. Echocardiogram. AOC, aortic wall calcification; PMAC, posterior mitral annular calcification; $A M A C$, anterior mitral annular calcification. 
Table 1 Clinical findings

\begin{tabular}{|c|c|c|c|c|c|c|c|c|c|c|c|c|c|c|}
\hline & \multirow{2}{*}{$\begin{array}{l}\operatorname{Age}(y) \\
(\overline{\mathrm{x}} \pm S D)\end{array}$} & \multicolumn{2}{|l|}{ Sex } & \multirow{2}{*}{ Total } & \multicolumn{4}{|c|}{ Associated conditions } & \multicolumn{4}{|c|}{ Murmurs } & \multicolumn{2}{|c|}{ Cardiomegaly } \\
\hline & & Men & Women & & $A O D M$ & Hypn & $C H D$ & $R H D$ & $A S$ & $A R$ & $M S$ & $M R$ & $\mathrm{X}-$ ray & Echo \\
\hline \multirow{2}{*}{$<70$} & $\begin{array}{l}\text { Group 1 } \\
(62 \pm 7)\end{array}$ & 22 & 19 & 41 & 5 & 10 & 11 & 1 & 23 & 2 & 3 & 9 & 35 & 31 \\
\hline & $\begin{array}{l}\text { Group 2 } \\
(62 \pm 6)\end{array}$ & 35 & 28 & 63 & 6 & 23 & 28 & 5 & 25 & 5 & 2 & 13 & 33 & 35 \\
\hline \multirow{2}{*}{$\geqslant 70$} & $\begin{array}{l}\text { Group 1 } \\
(76 \pm 6)\end{array}$ & 27 & 36 & 63 & 7 & 16 & 19 & 2 & 44 & 8 & 4 & 8 & 42 & 44 \\
\hline & $\begin{array}{l}\text { Group 2 } \\
(75 \pm 4)\end{array}$ & 26 & 32 & 58 & 6 & 14 & 20 & 2 & 29 & 6 & 2 & 8 & 32 & 28 \\
\hline \multirow{2}{*}{ Total } & $\begin{array}{l}\text { Group 1 } \\
(70 \pm 9)\end{array}$ & 49 & 55 & 104 & 12 & 26 & 30 & 3 & 67 & 10 & 7 & 17 & 77 & 75 \\
\hline & $\begin{array}{l}\text { Group 2 } \\
(68 \pm 8)\end{array}$ & 61 & 60 & 121 & 12 & 37 & 48 & 7 & 54 & 11 & 4 & 21 & 65 & 63 \\
\hline
\end{tabular}

, mean age; AODM, adult onset diabetes mellitus; AR, aortic regurgitation; AS, aortic stenosis; CHD, coronary heart disease ; Echo, echocardiogram; Hypn, hypertension; MR, mitral regurgitation; MS, mitral stenosis; RHD, rheumatic heart disease; SD, standard deviation.

12 patients in each group. Thirty patients in group 1 and 48 in group 2 had coronary heart disease. A history of rheumatic fever was present in only three patients of group 1 and seven of group 2 (Table 2).

Cardiomegaly detected by a cardiothoracic ratio on chest $x$-ray greater than 50 per cent was present in 77 patients in group 1 and 65 in group 2. Echocardiography showed that 48 patients in group 1 and 46 patients in group 2 had left atrial enlargement, 53 patients in group 1 and 49 in group 2 had left ventricular enlargement, 26 patients in group 1 and 30 in group 2 having both.

The types of conduction defects identified in groups 1 and 2 are summarised in Tables 3 and 4. Seventy-three of the 104 patients in group 1 had them, an incidence of 70 per cent ( 37 men and 36
Table 2 Correlation of associated conditions and conduction defects

\begin{tabular}{|c|c|c|c|c|}
\hline \multirow{2}{*}{$\begin{array}{l}\text { Associated } \\
\text { conditions }\end{array}$} & \multicolumn{2}{|c|}{$\begin{array}{l}\text { Patients with } \\
M A C \text { (104) }\end{array}$} & \multicolumn{2}{|c|}{$\begin{array}{l}\text { Patients without } \\
M A C(121)\end{array}$} \\
\hline & $C D(73)$ & $N C D(31)$ & $C D(41)$ & $N C D(80)$ \\
\hline $\begin{array}{l}\text { Hypertension } \\
\text { Diabetes } \\
\text { CHD } \\
\text { RHD } \\
\text { Total }\end{array}$ & $\begin{aligned} 18 & (24 \%) \\
9 & (12 \%) \\
23 & (31 \%) \\
2 & (3 \%) \\
52 & (70 \%)\end{aligned}$ & $\begin{array}{c}8(26 \%) \\
3(10 \%) \\
7(23 \%) \\
1(3 \%) \\
19(62 \%)\end{array}$ & $\begin{aligned} 13 & (32 \%) \\
4 & (10 \%) \\
13 & (32 \%) \\
2 & (5 \%) \\
32 & (79 \%)\end{aligned}$ & $\begin{aligned} 24 & (30 \%) \\
8 & (10 \%) \\
35 & (43 \%) \\
5 & (6 \%) \\
72 & (89 \%)\end{aligned}$ \\
\hline
\end{tabular}

CHD, coronary heart disease; CD, conduction defect; MAC, mitral annular calcification; NCD, no conduction defect; RHD, rheumatic heart disease.

women). There were 53 patients with isolated calcification of the posterior mitral annulus. Thirty-

Table 3 Correlation of conduction defects with age and sex

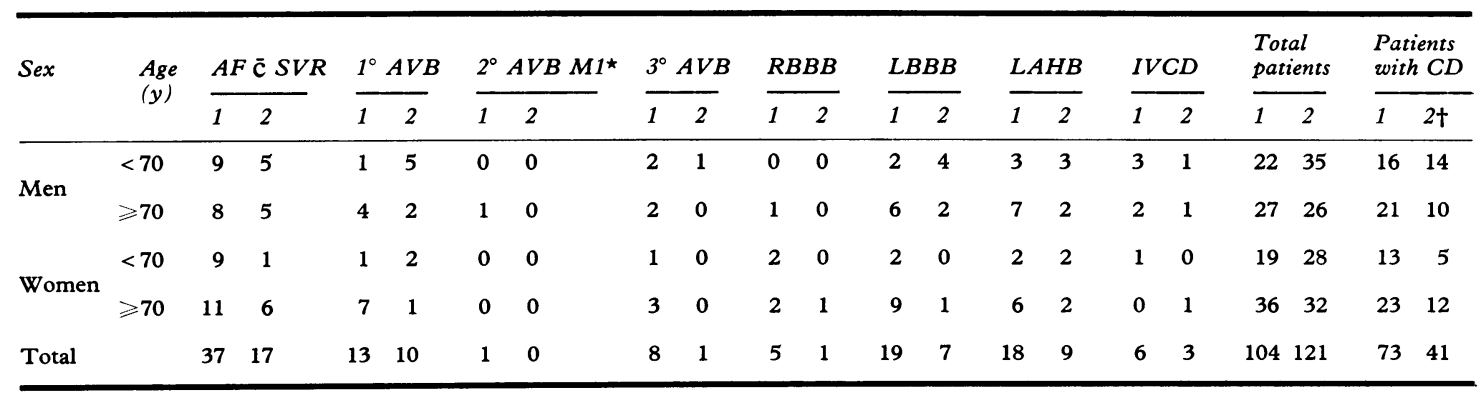

AF $\bar{c}$ SVR, atrial fibrillation with slow ventricular response; AVB, atrioventricular block; CD, conduction defect; IVCD, intraventricular conduction defect; LAHB, left anterior hemiblock; LBBB, left bundle-branch block; M1, Mobitz 1; RBBB, right bundle-branch block; 1, patients with mitral annular calcification; 2, patients without mitral annular calcification.

$\star$ None of the patients had Mobitz 2, $2^{\circ}$ AVB in either group. † Some patients with more than one conduction defect. 
Table 4 Correlation of conduction defects with type of calcification

\begin{tabular}{|c|c|c|c|c|c|c|c|c|c|c|c|}
\hline Type of calcification & $\begin{array}{l}\text { No. of } \\
\text { patients }\end{array}$ & $\begin{array}{l}\text { Patients } \\
\text { with } C D\end{array}$ & $A F \bar{c} S V R$ & $1^{\circ} A V B$ & $\begin{array}{l}2^{\circ} A V B \\
M 1^{\star}\end{array}$ & $3^{\circ} A V B$ & $R B B B$ & $L B B B$ & $L A H B$ & $I V C D$ & Combined \\
\hline $\begin{array}{l}\text { Ant MAC } \\
\text { Post MAC } \\
\text { Ant and post MAC } \\
\text { Total } \\
\text { MAC and AOC } \\
\text { AOC only (group 2) }\end{array}$ & $\begin{array}{r}8 \\
53 \\
43 \\
104 \\
68 \\
20\end{array}$ & $\begin{array}{r}8 \\
36 \\
29 \\
73 \\
49 \\
7\end{array}$ & $\begin{array}{r}1 \\
18 \\
18 \\
37 \\
19 \\
4\end{array}$ & $\begin{array}{r}4 \\
6 \\
3 \\
13 \\
11 \\
1\end{array}$ & $\begin{array}{l}0 \\
1 \\
0 \\
1 \\
1 \\
0\end{array}$ & $\begin{array}{l}1 \\
5 \\
2 \\
8 \\
4 \\
0\end{array}$ & $\begin{array}{l}0 \\
0 \\
5 \\
5 \\
4 \\
1\end{array}$ & $\begin{array}{r}3 \\
10 \\
6 \\
19 \\
16 \\
2\end{array}$ & $\begin{array}{r}2 \\
6 \\
10 \\
18 \\
12 \\
3\end{array}$ & $\begin{array}{l}1 \\
4 \\
1 \\
6 \\
4 \\
0\end{array}$ & $\begin{array}{r}3 \\
14 \\
12 \\
29 \\
20 \\
3\end{array}$ \\
\hline
\end{tabular}

AF c SVR, atrial fibrillation with slow ventricular response; Ant, anterior; AOC, aortic calcification; AVB, atrioventricular block; CD, conduction defect; IVCD, intraventricular conduction defect; LAHB, left anterior hemiblock; LBBB, left bundle-branch block; MAC, mitral annular calcification; M1, Mobitz 1; Post, posterior; RBBB, right bundle-branch block.

* None of the patients had Mobitz $2,2^{\circ}$ AVB in either group.

six of these $(68 \%)$ had conduction defects (Table 4). Both anterior and posterior mitral annular calcification was present in 43 patients, and $29(67 \%)$ of these had conduction defects. Isolated anterior mitral annular calcification was present in only eight patients. All of these were found to have conduction defects. Sixty-eight of the group 1 patients also had aortic calcification, and $49(72 \%)$ of these had conduction defects.

Of the 121 patients in group 2, only 41 (24 men and 17 women) had conduction defects, an incidence of 34 per cent compared with 70 per cent in group 1 . Aortic calcification in the absence of mitral annular calcification was present in 20 patients in group 2. Seven of these $(35 \%)$ had conduction defects, an incidence similar to that of the group in general.

There were 41 patients in group 1 who were under the age of 70 (Table 1). Of these, 16 of the 22 men $(73 \%)$ and 13 of the 19 women $(68 \%)$ had conduction defects, an overall incidence of 71 per cent. Of the 63 patients in group 1 over the age of 70 years, 21 of the 27 men $(78 \%)$ and 27 of the 36 women $(75 \%)$ were found to have conduction defects, an overall incidence of 76 per cent. In group 2, 63 patients were under 70 years of age. Of these, 14 of the 35 men $(40 \%)$ and five of the 28 women $(18 \%)$ had conduction defects, an overall incidence of 30 per cent. Of the 58 patients in group 2 over the age of 70, 10 of the 26 men (38\%) and 12 of the 32 women (38\%) had conduction defects, an overall incidence of 38 per cent. Thus, in group 1 age and sex appeared to have no influence on the occurrence of conduction defects.

\section{Discussion}

Bönninger ${ }^{1}$ first described mitral annular calcification as a pathological entity and pointed out its association with heart block. Since then, several reports describing the pathological and clinical features of mitral annular calcification have appeared. ${ }^{2-5}$ Pathological studies have shown that the deposits of calcium occur predominantly in the posterior portion of the annulus but may extend into the left atrium and left ventricle behind the mitral valve leaflets. ${ }^{45}$ The deposits of calcium may be extensive, 1 to $3 \mathrm{~cm}$ in diameter, and may encircle all or most of the mitral orifice. The calcium may extend as far as 3 to $4 \mathrm{~cm}$ into the adjacent myocardium. Calcific deposits may also extend into the membranous portion of the intraventricular septum in the vicinity of the bundle of $\mathrm{His}$ and its branches. Unlike secondary calcification in rheumatic heart disease, direct involvement of the mitral leaflets by these calcific deposits is infrequent. There have, however, been several cases of mitral annular calcification reported with commissural adherence of the mitral valve leaflets and calcific deposits in the anterior leaflet of the mitral valve as well as restriction of the motion of the posterior leaflets. ${ }^{14}$ Calcification of the aortic root has been a frequently associated finding in patients with mitral annular calcification, with an incidence as high as 74 per cent in one series. ${ }^{14}$ This is similar to the incidence of 65 per cent noted in our own study. The murmur of mitral regurgitation has frequently been noted in patients with mitral annular calcification, and the mitral regurgitation is felt to be the result of interference with the normal function of the mitral valve apparatus, either because of the lack of normal sphincter action of the annulus as a result of pronounced calcification or because of distortion of the mitral valve leaflets caused by heavy deposits of calcium in them. ${ }^{314}$ More recently, mitral valve obstruction with haemodynamically documented diastolic gradients across the mitral valve during diastole have been reported in four patients with massive mitral annular calcification. ${ }^{15}$ Though not proven, the mitral annular calcification may have been the source of many of the murmurs heard in our patients. However, the frequency of cardiac murmurs of all types, both systolic and diastolic, was similar in the patients without mitral annular calcification. 
Clinically, three methods are available for the detection of mitral annular calcification. Firstly, the chest $x$-ray, which, in our experience, was poorly sensitive, 30/104 $(31 \%)$. Secondly, there is image intensification fluoroscopy. This has been shown to have high sensitivity in diagnosing cardiac calcification. ${ }^{16}{ }^{12}$ Cardiae fturescopy and/or cineangiograms were available in 22 patients in group 1, and in all mitral annular calcification was detected. Lastly, many recent reports have described the usefulness of echocardiography. ${ }^{18-25}$

The incidence of mitral annular calcification has been reported to be 8 to 10 per cent in necropsied series over the age of 50 years and this incidence increases in a linear fashion with advancing age. ${ }^{4}$ Though the majority of reported series of mitral annular calcification have shown a much higher incidence in women, as high as 3 or 4 to 1 , our study disclosed an equal sex incidence. This is in agreement with the series of 87 cases reported by Perloff and Roberts ${ }^{14}$ in which a similar sex distribution was also found.

Several studies ${ }^{2926}$ have reported an increased incidence of mitral annular calcification in patients with diabetes mellitus and hypertension. Our study did not confirm this, nor was the incidence of coronary heart disease different in patients compared with controls.

A number of previous reports had noted cardiac conduction defects associated with a calcified mitral annulus, ${ }^{18101127}$ but the true incidence of them was uncertain. Our study showed cardiac conduction defects in 70 per cent of 104 patients, a figure significantly greater than in the control group.

Conduction defects are so common with mitral annular calcification probably because of the close association of the atrioventricular node and bundle of $\mathrm{His}$ to the cardiac fibrous skeleton. ${ }^{28}$ Others have suggested that the degenerative process within the mitral annulus may be associated with or accompanied by a "sclerodegenerative process" within the conduction system in these elderly patients. ${ }^{29} 30$ Though the exact mechanism underlying atrial fibrillation is not certain, it has been suggested that the diffuse conduction system disease may interrupt inter- and intra-atrial conduction. ${ }^{31}$ We postulate that involvement of the atrioventricular node and/or His bundle by annular calcification may be responsible for the presence of the slow ventricular response in these patients.

The incidence of conduction defects associated with calcification restricted to the posterior portion of the mitral annulus was similar to that found in patients having both anterior and posterior mitral annular calcification. Further, the presence of additional aortic calcification was not associated with a statistically significant increase in this incidence. Isolated aortic calcification in the absence of mitral annular calcification was found in 20 patients in group 2. The incidence of conduction defects in these patients was not significantly different from that found in the remainder of the group who did not have aortic calcification (35\% versus $34 \%$ ). All eight patients with anterior mitral annular calcification had conduction defects but the significance of this finding is uncertain because the number is small.

\section{Clinical implications}

Our study confirms the increased incidence of conduction defects in patients with mitral annular calcification, irrespective of age, sex, or associated conditions. Long-term follow-up studies are needed to determine how such conduction defects develop and progress. Patients with mitral annular calcification who do not have conduction defects in the surface electrocardiogram probably need closer observation and should be considered for ambulatory monitoring and/or electrophysiological investigation of the conduction system, especially if they have symptoms.

\section{References}

1 Bönninger M. Zwei Falle von Herzblock. Dtsch Med Wochenschr 1908; 34: 2292.

2 Fertman MH, Wolff L. Calcification of mitral valve. Am Heart $\mathcal{F}$ 1946; 31: 580-9.

3 Liu SF, Simon MA. Calcification of the mitral valve annulus and its relation to functional valvular disturbance. Am Heart $\mathcal{F}$ 1954 ; 48: 497-505.

4 Korn D, DeSanctis RW, Sell S. Massive calcification of the mitral annulus: a clinicopathological study of fourteen cases. $N$ Engl f Med 1962; 267: 900-9.

5 Pomerance A. Pathological and clinical study of calcification of the mitral ring. f Clin Pathol 1970; 23: 354-61.

6 Schott CR, Kotler MN, Parry WR, Segal BL. Mitral annular calcification. Arch Intern Med 1977; 137: 1143-50.

7 Gabor GE, Mohr BD, Goel PC, Cohen B. Echocardiographic and clinical spectrum of mitral annular calcification. Am f Cardiol 1976; 38: 836-42.

8 Gibson GA, Richie WT. Historic instances of Adams-Stokes syndrome due to heart-block. Edinb Med f 1909; 2: 507-25.

9 Geerling JC. Calcification in annular sclerosis of heart valves in arteriosclerosis. Ned Tijdschr Geneeskd 1929; 2: 5633.

10 Yater WM, Cornell VH. Heart block due to calcareous lesions of the bundle of His. Ann Intern Med 1935; 8: 777-89.

11 Comeau WJ. Paroxysmal complete heart block 
alternating with normal sinus rhythm and conduction. Am f Med Sci 1937; 194: 43-53.

12 Johnson RL, Averill KH, Lamb LE. Electrocardiographic findings in 67375 asymptomatic subjects. VII. Atrioventricular block. Am f Cardiol 1960; 6: 153-77.

13 Rosenbaum MB, Elizari MV, Lazzari JO. The hemiblocks. Oldsmar, Florida: Tampa Tracings 1970.

14 Perloff JK, Roberts WC. Mitral valvular disease: a clinicopathologic survey of the conditions causing the mitral valve to function abnormally. Ann Intern Med 1972; 77: 939-75.

15 Hammer WJ, Roberts WC, deLeon KC Jr. "Mitral stenosis" secondary to combined "massive" mitral annular calcific deposits and small, hypertrophied left ventricles. $A m$ 于 Med 1978; 64: 371-6.

$16 \mathrm{McCarthy} \mathrm{JH}$, Palmer FJ. Incidence and significance of coronary artery calcification. Br Heart $\mathcal{f} 1974 ; 36$ : 499-506.

17 Bartel AG, Chen JT, Peter RH, Behar VS, Kong Y, Lester RG. The significance of coronary calcification detected by fluoroscopy. A report of 360 patients. Circulation 1974; 49: 1247-53.

18 Okimato R, Iwasaki T, Mamata C, et al. Echocardiographic and phonocardiographic studies of mitral ring calcification. Cardiovasc Sound Bull (Tokyo) 1975; 5: 707.

19 D'Cruz IA, Cohen HC, Prabhu R, Bisla V, Glick G. Clinical manifestations of mitral annulus calcification with emphasis on its echocardiographic features. Am Heart f 1977; 94: 367-77.

20 Ewy G, Groves BM, Shy N, George W, Yauger H. Echocardiographic appearance of mitral annular calcification (abstract). Circulation 1975; 51 \& 52, suppl II: 179.

21 Graber HL, Fulkerson PK, Auseon JC. Echocardiographic demonstration of mitral annular calcification (abstract). Circulation 1975; 51 \& 52, suppl II : 191.
22 Dashkoff N, Karacushansky M, Fortuin NJ. Echocardiographic features of mitral annulus calcification (abstract). Circulation 1975; 51 \& 52, suppl II : 34.

23 Hirschfield DS, Emilson BB. Echocardiogram in calcified mitral annulus. Am f Cardiol 1975; 36: 354-6.

24 Dashoff N, Karacushansky M, Come PC, Fortuin NJ. Echocardiographic features of mitral annulus calcification. Am Heart f 1977; 94: 585-92.

25 Tanabe J, Ibrahim F. Echocardiographic findings of mitral anulus calcification. Special emphasis on clinical usefulness. In: Diethrich EB, ed. Noninvasive cardiovascular diagnosis. Baltimore: University Park Press, 1978: 383-92.

26 Tajik AJ, Giuliani ER, Frye RL, Davis GD, McGoon DC, Brandenburg RO. Mitral valve and/or annulus calcification associated with idiopathic subaortic stenosis (abstract). Circulation 1972; 45 \& 46, suppl II: 228.

27 Rytand DA, Lipstich LS. Clinical aspects of calcification of the mitral annulus fibrosus. Arch Intern Med 1946; 78: 544-64.

28 Lev M. Anatomic basis for atrioventricular block. Am f Med 1974; 37: 742-8.

29 Lenègre J. Etiology and pathology of bilateral bundle branch block in relation to complete heart block. Prog Cardiovasc Dis 1964; 6: 409-44.

30 Scarpa WJ. The sick sinus syndrome. Am Heart $\mathcal{F}$ 1976; 92: 648-60.

31 Fulkerson PK, Beaver BM, Auseon JC, Graber HL. Calcification of the mitral annulus. Etiology, clinical associations, complications and therapy. $\mathrm{Am} \mathrm{f} \mathrm{Med}$ 1979; 66: 967-77.

Requests for reprints to $\mathrm{Dr}$ Chandra $\mathrm{K}$ Nair, Creighton University Cardiac Center, 601 No. 30th Street, Omaha, Nebraska 68131, USA. 